\title{
Influence of slot opening width and rotor pole radius on the torque of PMSM
}

\author{
J. A. Güemes ${ }^{1}$, P. M. García ${ }^{2}$, A. M. Iraolagoitia ${ }^{1}$, J. J. Ugartemendia ${ }^{2}$ \\ ${ }^{1}$ Department of Electrical Engineering \\ E.U.I.T.I, University of the Basque Country \\ Plaza de la Casilla 3, 48012 Bilbao (Spain)
}

Phone:: +34 946014 363, Fax number: +34 946014 300, e-mail: joseantonio.guemes@ehu.es, ana.iraolagoitia@ehu.es

\author{
${ }^{2}$ Department of Electrical Engineering \\ Escuela Universitaria Politécnica, University of the Basque Country \\ Plaza de Europa 1, 20018 San Sebastián (Spain) \\ Phone: +34 943017 234, Fax number: +34 943017 130, e-mail: pedromaria.garcia@ehu.es, juanjo.ugartemendia@ehu.es
}

\begin{abstract}
Influence of the slot opening width and rotor pole radius on the cogging torque and total torque developed by a three-phase permanent magnet synchronous motor (PMSM) is investigated. The number of motor poles and number of stator slots are fixed. Finite element technique is used for the computation of machine characteristic. Core saturation is directly considered in the magnetic field calculation. Formulation based on two methods, virtual work and Maxwell stress tensor is used to find the torque.
\end{abstract}

\section{Key words}

Cogging torque, finite element method, Maxwell stress, permanent magnet synchronous motor, ripple cogging, virtual work.

\section{Introduction}

PMSMs are widely used in many industrial applications for their compactness, simple mechanical construction, absence of moving contacts, easy maintenance, good reliability, highly efficiency and high torque density. As their cost continues decreasing they have the opportunity to become a dominant force in the industrial applications market [1], [2].

One of the most important problems in permanent magnet (PM) motors is the pulsating torque which is inherent in their design. This ripple is parasitic, and can lead to mechanical vibration, acoustic noise, and problems in drive systems. Minimizing this ripple is of great importance in the design of PMSMs [3], [4]. The pulsating torque should be specially analysed for applications of constant speed or high-precision position control, especially at low speed [5], [6].
There are three sources of torque ripple coming from the machine: a) cogging torque, b) difference between permeances of the air gap in the $d$ - and $q$-axis (reluctance torque), and c) distortion of the magnetic flux density waveform in the air gap [7]. Cogging torque is the consequence of the interaction (magnetic attraction) between the rotor-mounted permanent magnets field and stator slots, which produces reluctance variations with the rotor position; it is independent of stator current. It manifests itself by the tendency of the rotor to align in a number of stable positions even when the machine is unexcited, the results is a pulsating torque which does not contribute to the net effective torque. It can be shown that in a motor with integral slot-windings, the instantaneous cogging torque is zero when a) the rotor pole axes are aligned with the centres of teeth, and b) the rotor pole axes are aligned with the centres of slots.

In the literature, numerous methods for reducing the cogging torque, such as employing a fractional number of slots per pole, skewing of magnets and/or slots, displacing and shaping the magnets, optimizing the magnet pole-arc-to-pole-pitch ratio, introducing auxiliary slots or teeth, etc, have been proposed [3]-[6], [8]-[11].

Use of fractional number of slots per pole reduces the amplitude of the cogging torque but also increases the fundamental order (deformation of the waveform of the magnetic flux density in the air gap of the machine), since the stator slots are located at different relative circumferential positions with respect to the edges of the magnets [8].

The main objective of the paper is to investigate the influence of the slot opening width and rotor pole radius 
on the cogging torque and torque ripple of a 12-pole, 36slot PMSM. Magnetic vector potential waveforms in the air gap are also obtained and compared.

\section{Formulation}

The two most widely used methods for computing the torque of rotating electric machines are the virtual work and Maxwell stress methods [12] - [16].

\section{A. Virtual work method}

It can be shown that the total force in direction $p$ on a component of a system is found by computing the change in the stored magnetic energy or co-energy of the system, when the component is displaced in direction $p$. Mathematically can be written as:

$$
F_{p}=-\left.\frac{\partial W(\phi, p)}{\partial p}\right|_{\phi=c o n s t}=\left.\frac{\partial W_{c}(i, p)}{\partial p}\right|_{i=c o n s t}
$$

where $F_{\mathrm{p}}$ is the component of the total force in the direction of $p, W$ is the stored magnetic energy and $W_{\mathrm{c}}$ is the magnetic co-energy.

Finally, the global torque developed by a rotating electric machine, can be calculated as the partial derivative of the magnetic co-energy with respect to the virtual displacement of the rotor.

$$
T=\frac{\partial W_{c}}{\partial \theta}
$$

where $\theta$ is the rotor angular displacement.

\section{B. Maxwell stress method}

The use of the Maxwell stress tensor is simple from a computational perspective, since it requires only the local flux density distribution along a contour.

Total force can be calculated by means of the following expression:

$$
F=\int_{s} \frac{1}{2 \mu_{o}}\left(B_{n}^{2}-B_{t}^{2}\right) d s \cdot \boldsymbol{n}+\int_{s} \frac{1}{\mu_{o}} B_{n} B_{t} d s \cdot \boldsymbol{t}
$$

where $B_{\mathrm{n}}$ and $B_{\mathrm{t}}$, are the normal and tangential components of the magnetic flux density $\left(\mathrm{B}_{\mathrm{n}}\right.$ and $\mathrm{B}_{\mathrm{t}}$, respectively), $\boldsymbol{n}$ and $\boldsymbol{t}$ are the normal and tangential unit vectors to the surface $s$ ( $\boldsymbol{n}$ and $\boldsymbol{t}$, respectively) and $s$ is the surface of integration around the air gap region.

Taking into account that in rotating electric machine only the tangential component of the Maxwell stresses generates torque, we have:

$$
F_{t}=\int_{S} \frac{1}{\mu_{o}} B_{n} B_{t} d s
$$

For two-dimensional plane models the integration surface is transformed into a closed contour of radius $r$ (air gap region centre). Calculating the tangential force in each point of the round path, by means of the following expression:

$$
F_{t}=\frac{B_{n} \cdot B_{t}}{\mu_{o}}
$$

As the magnetic flux density is calculated at discrete points in the air gap region, the torque can be obtained by means of the following expression:

$$
T=r\left(\sum \frac{1}{\mu_{o}} B_{n} \cdot B_{t}\right) d \cdot l
$$

where $r$ is the radius of the circular path taken, $d$ is the length of the path and $l$ is the axial length of the magnetic sheet core.

In this paper, the co-energy in the air gap of the motor and also the normal and tangential components of the magnetic flux density are calculated utilizing the finite element technique.

The electric machine simulation using finite element method is considered a very important tool for the calculation engineer as it allows getting to know with a quite good approximation the different machine parameters, as well as its behaviour under extreme working conditions.

\section{Motor analyzed}

Cross section of 36-slot, 12-pole PMSM, discussed in this paper is shown in Fig. 1. Each rotor pole contains a magnet permanent type neodymium-iron-boron $(\mathrm{NdFeB})$ that is magnetized across their shorter dimension along the direct $(d)$ axis.

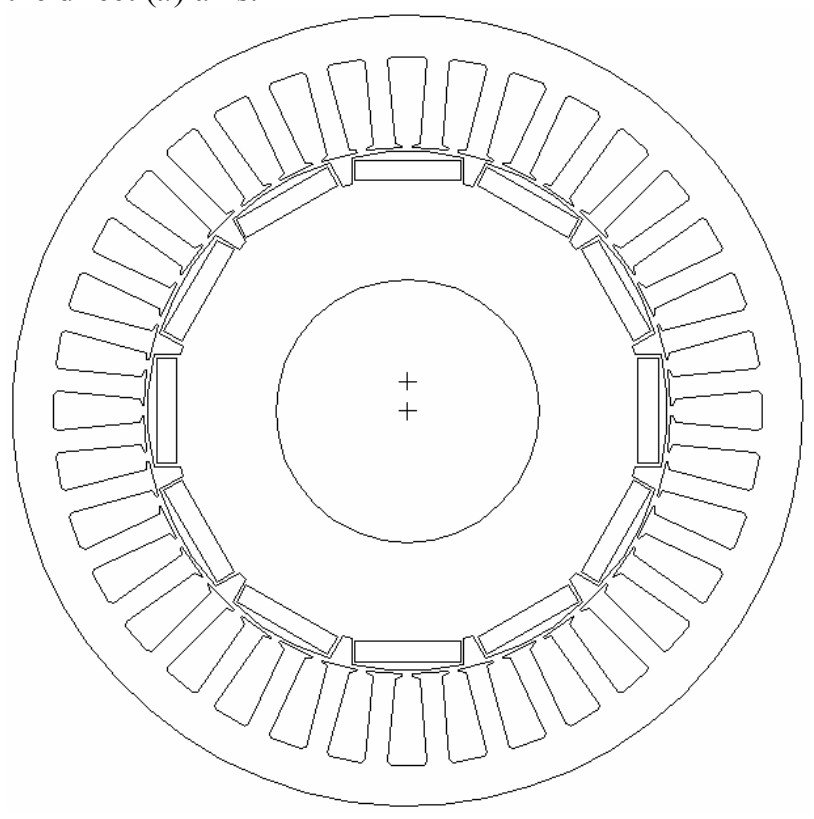

Fig.1. Cross section of a 12-pole, 36-slot motor 
Table I shows the main design parameters of the studied motor.

TABLE I. - Details of the Analyzed Motor

\begin{tabular}{|l|l|}
\hline Connection & Star \\
\hline Controller device input voltage (line-to-line) & $400 \mathrm{~V}$ \\
\hline Frequency of the controller device input voltage & $50 \mathrm{~Hz}$ \\
\hline Frequency of the motor input voltage & $19 \mathrm{~Hz}$ \\
\hline Power rating (referred to $16 \mathrm{~Hz}$ ) & $6 \mathrm{~kW}$ \\
\hline Current rating & $16.6 \mathrm{~A}$ \\
\hline Number of poles & 12 \\
\hline Number of stator slots & 36 \\
\hline Number of slots per pole and per phase & 1 \\
\hline Shaft diameter & $80 \mathrm{~mm}$ \\
\hline Rotor outside diameter & $158 \mathrm{~mm}$ \\
\hline Stator inner diameter & $160 \mathrm{~mm}$ \\
\hline Stator outside diameter & $240 \mathrm{~mm}$ \\
\hline Permanent magnet material & $\mathrm{NdFeB}$ \\
\hline Magnet thickness & $6 \mathrm{~mm}$ \\
\hline Width of magnet & $32 \mathrm{~mm}$ \\
\hline Coercive magnetizing intensity & $920 \mathrm{kA} / \mathrm{m}$ \\
\hline Remanent flux density & $1.16 \mathrm{~T}$ \\
\hline
\end{tabular}

\section{Simulation and results}

Finite element technique is used for the computation of the machine characteristic. A non-lineal field analysis is carried out for calculating the magnetic flux density in each one of the model nodes.

The model utilized is constituted by a transverse section through the middle of the motor $\left(360^{\circ}\right.$ geometry). The space of air surrounding the motor has to be taken into account too. The models of finite element used are twodimensional plane (the results are valid for stators and rotors without any skew).

The mesh used is shown in Fig. 2.

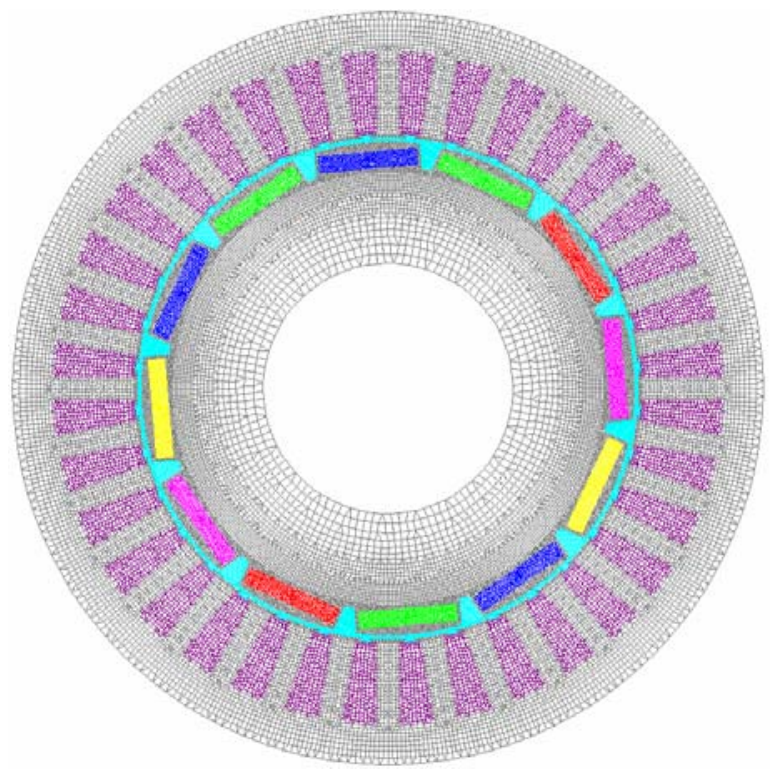

Fig. 2. Finite element mesh
The meshes utilized in the air gap are shown in Fig. 3 (a- the torque was calculated using the virtual work method, and b- the torque was calculated using the Maxwell stress method).

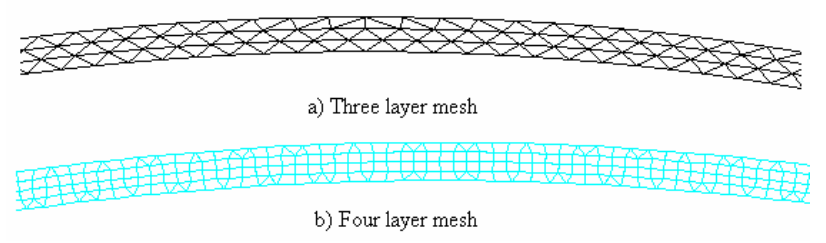

Fig. 3. Meshes used in the air gap

\section{A. Cogging torque}

The effect of the slot opening width and rotor pole radius (see Fig. 4) on the cogging torque, for the previously shown motor, is investigated in this section.

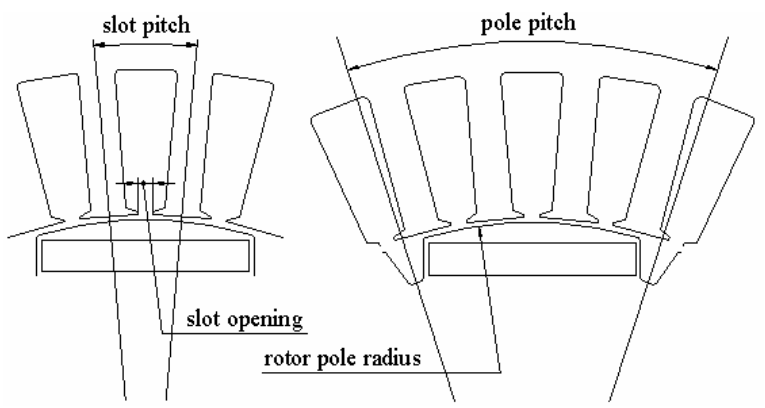

Fig. 4. Slot opening width and rotor pole radius

To calculate the cogging torque, the behaviour of the motor for different rotor positions, when there is no current in the windings, is simulated; at each rotor position the meshing is renewed.

Fig. 5 shows the cogging torque as a function of mechanical angle for different slot opening widths (SOW) when the rotor pole radius (RPR) is $70 \mathrm{~mm}$. The origin of coordinates corresponds to the rotor position in which the permanent magnets are centred with stator slots. We can see that the cogging torque is very dependent on the slot opening width. The cogging torque magnitude is reduced by $64 \%$ for SOW $=2 \mathrm{~mm}$ compared to the cogging torque magnitude obtained with SOW $=4 \mathrm{~mm}$. It is easier to insert coils with slot opening widths of $2.5 \mathrm{~mm}$ or higher.

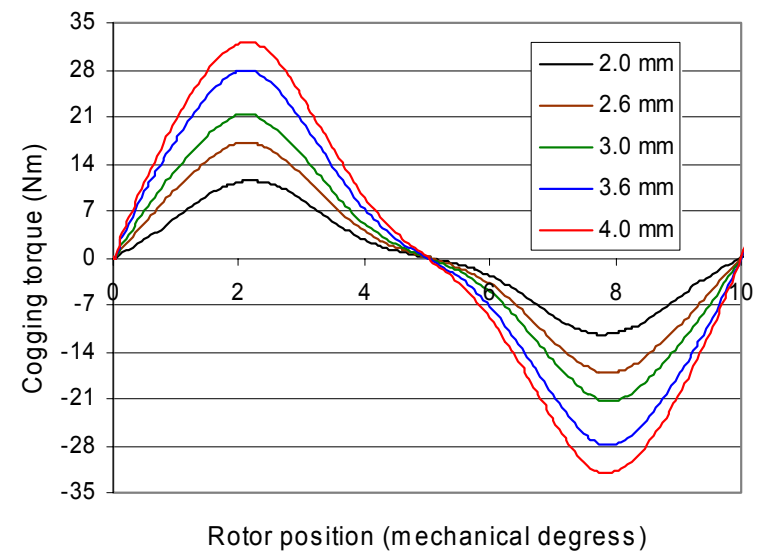

Fig. 5. Cogging torque (rotor pole radius equal to $70 \mathrm{~mm}$ ) 
Fig. 6 shows the cogging torque as a function of mechanical angle for different rotor pole radius when the slot opening width is of $3 \mathrm{~mm}$. The cogging torque is lower when the rotor pole radius decreases. The magnitude of the cogging torque is reduced by $38 \%$ for $\mathrm{RPR}=65 \mathrm{~mm}$ compared to the cogging torque magnitude obtained with $\mathrm{RPR}=79 \mathrm{~mm}$.

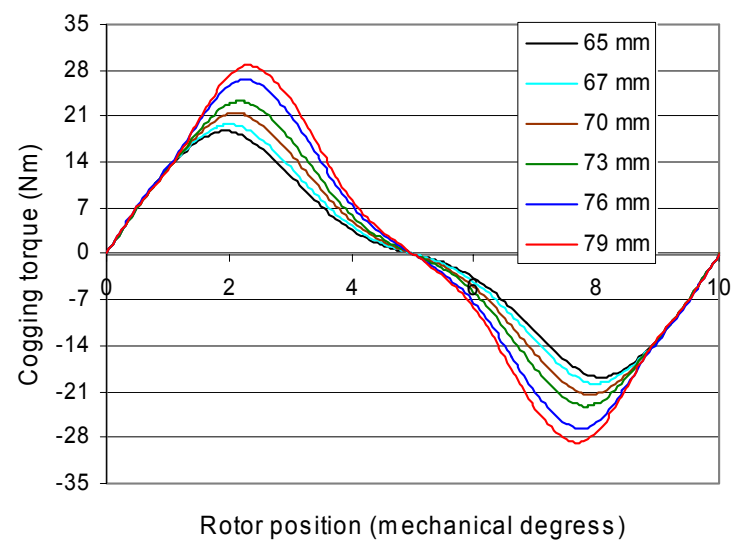

Fig. 6. Cogging torque (slot opening width equal to $3 \mathrm{~mm}$ )

The virtual work method was used to calculate the torque shown in the Figs. 5 and 6.

Figure 7 shows the cogging torque obtained for the virtual work and Maxwell stress methods, V and $\mathrm{M}$, respectively.

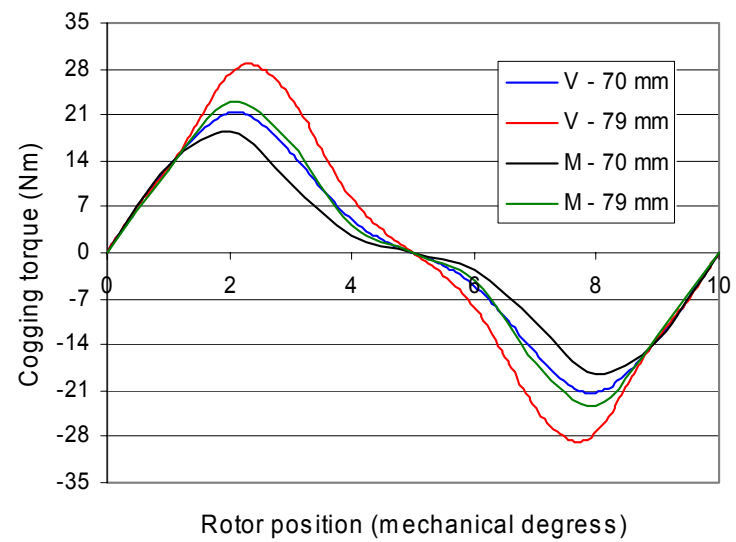

Fig. 7. Cogging torque (slot opening width equal to $3 \mathrm{~mm}$ )

\section{B. Torque ripple}

Electromagnetic torque developed by the motor is calculated simulating the load behaviour of the motor, for different positions of the rotor, when the flux armature and excitation are perpendicular $\left(I_{\mathrm{d}}=0, I_{\mathrm{q}},=I\right)$.

Figure 8 shows the electromagnetic torque waveform obtained, once the load analysis of the motor has been carried out. The torque was calculated using the Maxwell stress method.

We can observe that the frequency of the waveforms of the cogging torque and also of the torque ripple is the same (motor with number of slots per pole and phase equal to 1$)$.

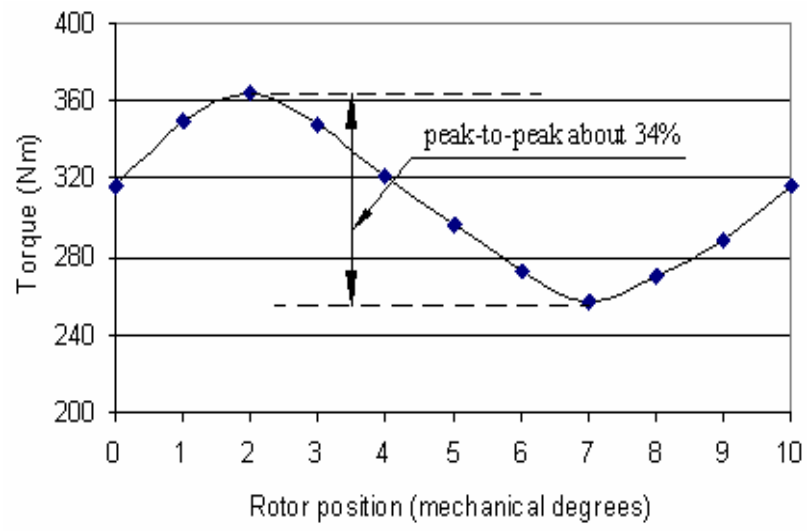

Fig. 8. Electromagnetic torque (rotor pole radius equal to $79 \mathrm{~mm}$ and slot opening width equal to $3 \mathrm{~mm}$ )

The torque ripple factor $\left(t_{\mathrm{r}}\right)$ can been defined as [7]:

$$
t_{r}=\frac{T_{\max }-T_{\min }}{T_{a v}} \cdot 100
$$

where $T_{\max }, T_{\min }$ and $T_{\text {av }}$ are, respectively, the maximal, minimal and average values of the torque.

Table II shows the useful torque ripple factor when the rotor pole radius is modified. We can deduce that the torque ripple factor is lower when the rotor pole radius decreases.

TABLE II. - Useful Torque Ripple Factor (slot opening width equal to $3 \mathrm{~mm}$ )

\begin{tabular}{|c|c|c|c|c|}
\hline $\begin{array}{c}\text { Rotor pole radius } \\
(\mathrm{mm})\end{array}$ & $\begin{array}{c}T_{\max } \\
(\mathrm{Nm})\end{array}$ & $\begin{array}{c}T_{\min } \\
(\mathrm{Nm})\end{array}$ & $\begin{array}{c}T_{\mathrm{av}} \\
(\mathrm{Nm})\end{array}$ & $\begin{array}{c}t_{r} \\
(\%)\end{array}$ \\
\hline 79 & 363.7 & 257.4 & 308 & 34.5 \\
\hline 70 & 358.7 & 262.0 & 308 & 31.3 \\
\hline
\end{tabular}

The cogging torque factor $\left(t_{\mathrm{c}}\right)$ can been defined as following:

$$
t_{c}=\frac{T_{c \max }-T_{c \min }}{T_{a v}} \cdot 100
$$

where $T_{\text {cmax }}$, and $T_{\text {cmin }}$ are, respectively, the maximal and minimal values of the cogging torque.

Table III shows the cogging torque factor when the rotor pole radius is modified. We can deduce that the cogging torque factor is lower when the rotor pole radius decrease.

TABLE III. - Useful Cogging Torque Factor (slot opening width equal to $3 \mathrm{~mm}$ )

\begin{tabular}{|c|c|c|c|c|}
\hline $\begin{array}{c}\text { Rotor pole radius } \\
(\mathrm{mm})\end{array}$ & $\begin{array}{c}T_{\max } \\
(\mathrm{Nm})\end{array}$ & $\begin{array}{c}T_{\min } \\
(\mathrm{Nm})\end{array}$ & $\begin{array}{c}T_{\mathrm{av}} \\
(\mathrm{Nm})\end{array}$ & $\begin{array}{c}T_{c} \\
(\%)\end{array}$ \\
\hline 79 & 23.2 & -23.2 & 308 & 15 \\
\hline 70 & 18.6 & -18.6 & 308 & 12 \\
\hline
\end{tabular}




\section{Magnetic vector potential and magnetic flux density.}

Figure 9 shows the air-gap magnetic vector potential waveforms obtained, once the no-load and load analysis of the motors have been carried out. The origin of coordinates corresponds to the rotor position in which the permanent magnets are centred with stator teeth.

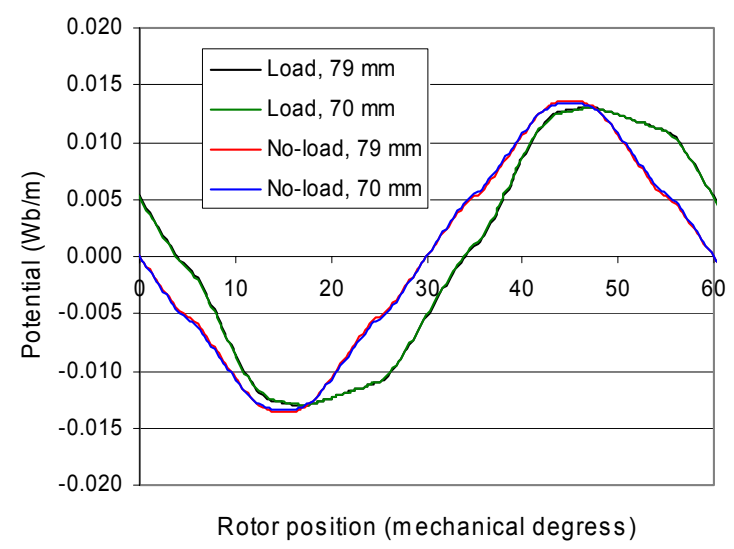

Fig. 9. Magnetic vector potential (slot opening width equal to $3 \mathrm{~mm}$ and rotor pole radius of 70 and $79 \mathrm{~mm}$ )

Figure 10 shows the normal component of the magnetic flux density in the centre of air gap versus rotor position.

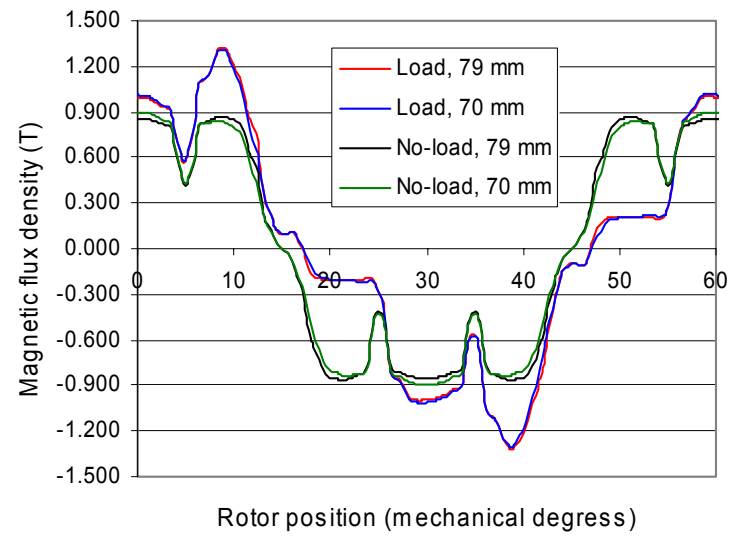

Fig. 10. Magnetic flux density (slot opening width equal to $3 \mathrm{~mm}$ )

The magnet skew can be effective for reducing the harmonic content in the flux linkage and back emf waveform.

\section{Conclusions}

Utilizing the finite element technique the effect of slot opening width and rotor pole radius on the cogging torque and torque ripple has been investigated. Cogging torque is lower when the slot opening width decreases. Cogging torque and ripple torque are lower when the rotor pole radius decreases.

\section{References}

[1] T. F. Chan, L. L. Lai, and Lie-Tong Yan, "Performance of a three-phase $\mathrm{AC}$ generator with inset $\mathrm{NdFeB}$ permanentmagnet rotor", IEEE Trans. Energy Conversion, vol. 19, no.1, pp. 88-94, 2004.

[2] C. Bretón, J. Bartolomé, J. A. Benito, G. Tassinario, I. Flotats, C. Lu, and B. J. Chalmers, "Influence of machine symmetry on reduction of cogging torque in permanent magnet brushless motors", IEEE Trans. Magnetics, vol. 36 , no. 5, pp. 3819-3823, 2000.

[3] L. Dosiek, and P. Pillay, "Cogging torque reduction in permanent magnet machines", IEEE Trans. Industry Application, vol. 43, no. 6, pp. 1656 - 1571, 2007.

[4] Z.Q. Zhu, and D. Howe, "Influence of design parameters on Cogging torque in permanent magnet machines", IEEE Trans. Energy Conversion, vol. 15, no. 4, pp. 407-412, 2000.

[5] L. Wu, W. Jin, J. Ni, and J. Ying, "A Cogging Torque Reduction Method for Surface Mounted Permanent Magnet Motor", in Proc. International Conference on Elctrical Machines and Systems, Seoul - Korea, 2007, pp. 769-773.

[6] R. Lateb, N. Takorabet, and F. Meibody-Tabar, "Effect of magnet segmentation on the cogging torque in surfacemounted permanent-magnet motors", IEEE Trans. Magnetics, vol. 42, no. 3, pp. 442-445, 2006.

[7] J.F. Gieras, and M. Wing, "Permanent magnet motor technology. Design and applications", Marcel Dekker, Inc, New York, 2002.

[8] Z.Q. Zhu, S. Ruangsinchaiwanich, and D. Howe, "Synthesis of cogging-torque waveform form analysis of a single stator slot", IEEE Trans. Industry Applications, vol. 42, no. 3, pp. 650-657, 2006.

[9] P. Salminen, J. Pyrhönen, F. Libert, and J. Soulard, "Torque ripple of permanent magnet machines with concentrated windings", in Proc. International Symposium on Electromagnetic Fields in Mechatronics, Electrical and Electronic Engineering, Baiona, Spain, Sep. 2005.

[10] C. Schlensok, M. Herranz-Gracia, and K. Hameyer, "Combined numerical and analytical method for geometry optimization of a PM motor", IEEE Trans. Magnetics, vol. 42, no. 4, pp. 1211-1214, 2006.

[11] R. Islam, I. Husain, A. Fardoun, and K. McLaughlin, "Permanent-magnet synchronous motor magnet designs with skewing for torque ripple and cogging torque reduction", IEEE Trans Industry Applications, vol. 45, $\mathrm{n}^{\circ}$. 1, pp. 152-160, 2009.

[12] J. L. Coulomb, and G. Meunier, "Finite element implementation of virtual work principle for magnetic o electric force and torque computation", IEEE Trans. Magnetics, vol. 20, no. 5, pp. 1894-1896, 1984.

[13] S. Salon, S. Bhatia, and D. Burow, "Some aspects of torque calculations in electrical machines", IEEE Trans. Magnetics, vol. 33, no, 2, pp. 2018-2021, 1997.

[14] R. Mertens, U. Pahner, K. Hameyer, and R. Belmans, "Force calculation based on a local solution of Laplace's equation", IEEE trans. Magnetics, vol. 33, no. 2, pp. 1216-1218, 1997.

[15] J. Rizk and M. Nagrial, "Torque calculation in permanent magnet machines using finite element method", IPEMC, pp. 906-910, 1997.

[16] R. Castillo, and J. M. Cañedo, "A 2-D Finite-element formulation for unambiguous torque calculation", IEEE Trans. Magnetics, vol. 44, no. 3, pp. 373-376, 2008. 